https://artnodes.uoc.edu

\title{
Arte contemporáneo y arquitecturas del cuerpo contagiado (huésped-hospedador) bajo la narrativa del sanatorio antituberculoso*
}

\author{
Gloria Lapeña Gallego \\ Universidad de Granada
}

Fecha de presentación: septiembre de 2020

Fecha de aceptación: noviembre de 2020

Fecha de publicación: enero de 2021

\section{Cita recomendada}

Lapeña Gallego, Gloria. 2021. «Arte contemporáneo y arquitecturas del cuerpo contagiado (huésped-hospedador) bajo la narrativa del sanatorio antituberculoso». En: Benítez, Laura; Berger, Erich (coord.) «Artes en tiempos de pandemia». Artnodes, núm. 27: 1-9. U0C. [Consulta: dd/mm/aa]. http://doi.org/10.7238/a.v0i27.373917

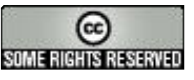

Los textos publicados en esta revista están sujetos -si no se indica lo contrario- a una licencia de Reconocimiento 4.0 Internacional de CreativeCommons. La licencia completa se puede consultar en https://creativecommons.org/licenses/by/4.0/deed.es_ES.

\section{Resumen}

La visualización del interior anatómico, los avances biomédicos en enfermedades infecciosas y la preocupación por un cuerpo sano protegido del contagio han condicionado el diseño y los materiales de la arquitectura moderna. Además, ha despertado el interés del artista hacia la relación existente entre el enfermo con su entorno perceptible y con su interior invisible. Proponemos como objeto de investigación aportaciones al arte contemporáneo basadas en el entorno hospitalario como constructo preventivo-curativo de las tres grandes enfermedades transmisibles actuales: tuberculosis, SIDA y SARS. Los objetivos son justificar, a través del 


\title{
artnodes
}

https://artnodes.uoc.edu

Arte contemporáneo y arquitecturas del cuerpo contagiado (huésped-hospedador) bajo la narrativa del sanatorio antituberculoso

análisis de una selección de proyectos, la concepción del cuerpo como huésped de espacios arquitectónicos concebidos para su curación o prevención del contagio, e identificar el cuerpo como hospedador examinado e invadido. Demostramos el cambio de paradigma del primigenio sanatorio antituberculoso, reflejado en las experiencias indirectas y directas de artistas ingresados en instituciones cerradas y sometidos al control médico, hasta los actuales hospitales Big Data, pasando por el padecimiento del cuerpo con SIDA en su domicilio. La pertinencia de este estudio radica en la reconstrucción de la evolución del cuerpo-individuo aislado en el sanatorio antituberculoso hasta un cuerpo-colectivo contenedor de datos que son procesados para su uso como control de espacios más amplios, países y continentes, giro importante que no escapa a la mirada del artista.

\section{Palabras clave}

arte contemporáneo, arquitectura hospitalaria, enfermedades infecciosas, cuerpo transparente.

\section{Contemporary art and architectures of the infected (host-host) under the narrative of the tuberculosis sanatorium}

\begin{abstract}
The visualization of the anatomical inside, the biomedical advances in infectious diseases and the concern for a healthy body protected from contagion have conditioned the design and materials of modern architecture. In addition, it has aroused the artist's interest in the relationship between the patient and his perceptible environment and his invisible interior. We propose as an object of research the contributions to contemporary art based on the hospital environment as a preventive-curative construct of the three major current communicable diseases: tuberculosis, AIDS and SARS. The aims are to justify, through the analysis of a selection of projects, the conception of the body as a host of architectural spaces that are conceived for its cure or prevention of contagion, and to identify the body as an examined and invaded host. We demonstrate the paradigm shift from the original tuberculosis sanatorium, reflected in the indirect and direct experiences of confined artists in gated institutions and subjected to medical control, up to the current Big Data hospitals, going through the suffering of the body with AIDS at home. The relevance of this study lies in the reconstruction of the evolution of the isolated individual-body in the tuberculosis sanatorium to a container collective-body of data that is processed to be used for the control of larger spaces, countries and continents, an important turn that does not escape the artist's gaze.
\end{abstract}

\section{Keywords}

contemporary art, hospital architecture, infectious diseases, transparent body

\section{Introducción}

Beatriz Colomina, en un capítulo de su obra La domesticidad en Guerra (2006a), y más recientemente en su libro X-Ray Architecture (2019), revisa la doble relación entre la construcción de los sanatorios antituberculosos y el descubrimiento de los rayos X por Röntgen en 1895. En primer lugar, advierte una nueva forma de vigilancia radiográfica corporal en plena posguerra, que se mantiene y amplía en la actualidad en el control en fronteras y aeropuertos. Además, apunta que las bases científicas del contagio y la prevención de la tuberculosis van a definir aspectos no solo de la construcción hospitalaria, sino de manera general de la arquitectura moderna. Un ejemplo que cita la arquitecta es la hipotética ciudad de estructura antropomórfica descrita por Le Corbusier en su obra, que inicia en
1930 y que culmina en 1935 con la publicación del libro La Ville Radieuse. El diseño se fundamenta en textos médicos con el fin de transformar las casas de habitar en casas de curar. Para evitar la humedad, uno de los factores que fomentan el reumatismo y la tuberculosis, se incorporan pilotes que elevan del suelo el volumen de edificio y grandes ventanas horizontales para conseguir la entrada de la luz solar, así como la presencia de azoteas transitables ajardinadas. Estas bases teóricas se materializan en la construcción del reconocido sanatorio antituberculoso de Alvar Aalto en Paimio (Finlandia) entre 1929-1933 y son avaladas en la primera reunión (1962) de un grupo de arquitectos de reconocimiento mundial constituido en el denominado Team 10, donde se propone como debate el concepto de ciudad dentro de otra ciudad (Iglesias Picazo, 2011). Los primigenios sanatorios antituberculosos se integran en los hospitales, que 


\section{artnodes}

https://artnodes.uoc.edu

conforman ciudades sanitarias con todos los servicios asistenciales incluidos los laboratorios de diagnóstico e investigación, y los periodos de ingreso se acortan al máximo para completarse en el domicilio del paciente.

Al igual que la construcción de los primeros sanatorios antituberculosos influyó en el diseño de un modelo de hospital basado en la finalidad curativa de los edificios, los avances en el cultivo del Mycobacterium tuberculosis, el descubrimiento del primer antibiótico, la descripción de la estructura molecular del ADN y su aplicación en técnicas de PCR, han marcado importantes hitos en el desarrollo de la medicina. Actualmente, la tuberculosis es una enfermedad bacteriana emergente reactivada por el uso indiscriminado de antibióticos y por la difusión del virus del SIDA. La lucha frente a estos y otros procesos infectocontagiosos como el SARS-CoV-2, responsable de la actual pandemia vírica COVID-19, se centra en evitar el acceso del microorganismo al cuerpo por barreras físicas externas, en prevenir la acción del agente mediante la vacunación o en tratar la enfermedad mediante nuevos fármacos. Las tres acciones aluden a dos aspectos espaciales que toma el cuerpo humano como referencia, nominados con el término host, utilizado en medicina como «huésped» y también como «anfitrión» (Navarro, 1997).

El interés hacia la enfermedad y los modos de habitar y hospedar del enfermo como tema en las prácticas artísticas contemporáneas ha propiciado la investigación multidisciplinar. Se incluyen ciencias del ámbito de las humanidades como la antropología en el análisis de la estigmatización que se asignan a ciertas enfermedades (Del Río Almagro y Rico Cuesta, 2019), la filosofía y el estudio del lenguaje metafórico que rodea los términos médicos (Sontag, 1979) y las ciencias experimentales, en las que el artista incorpora técnicas y/o conceptos propios de la biotecnología, e incluso propone planteamientos éticos activistas, configurando un vasto repertorio del denominado bioarte (López del Rincón, 2015).

\section{Objeto de estudio, hipótesis y objetivos}

En el presente estudio proponemos como objeto de investigación una serie de aportaciones al arte contemporáneo basadas en la ciencia médica y el entorno hospitalario como constructo preventivo-curativo. Acotamos la prolífica producción artística actual sobre enfermedad a aquellas obras que relacionan de manera simbiótica arquitectura hospitalaria y cuerpo enfermo contagiado, incidiendo especialmente en la tuberculosis, el Síndrome de Inmunodeficiencia Adquirida (SIDA) y el Síndrome Agudo Respiratorio Severo (SARS), tres enfermedades transmisibles presentes en la sociedad del siglo xx y xxl.

Partimos de la hipótesis de que el análisis de las prácticas artísticas sobre enfermedades infecciosas puede realizarse en términos arquitectónicos, ya que el cuerpo enfermo infectado o el cuerpo sano potencialmente receptor de contagio es aislado en un espacio físico
Arte contemporáneo y arquitecturas del cuerpo contagiado (huésped-hospedador) bajo la narrativa del sanatorio antituberculoso

(cuerpo como huésped) y tratado para reestablecer el equilibrio de sus órganos internos, alterados por otros seres vivos que contiene (cuerpo como hospedador).

Planteamos dos objetivos que tratamos en sendos apartados ilustrados con ejemplos de producciones de arte contemporáneo. El objetivo del primero es analizar el tratamiento que damos al cuerpo como huésped de espacios arquitectónicos concebidos para la curación del enfermo infectado o para la prevención del contagio. En el segundo apartado proponemos identificar el enfermo potencial o real como un cuerpo que puede ser visualizado internamente mediante la tecnología del análisis de imagen, examinado para la obtención de datos e invadido por agentes externos extraños.

\section{El cuerpo enfermo como huésped. "Alojarse en»}

El discurso arquitectónico ha estado siempre asociado al cuerpo humano. La obra Edificios-cuerpo. Cuerpo humano y arquitectura: analogías, metáforas, derivaciones (Ramírez, 2003) resume la relación cuerpo-arquitectura apoyándose en múltiples ejemplos gráficos. El historiador y crítico de arte recupera el cuerpo real (carne, huesos, vísceras) y lo antepone al cuerpo mediático-ficticio en crisis, origen de la soledad de la humanidad rodeada de multitud. Ese cuerpo real ha sido llevado a la categoría de obra de arte a lo largo de la historia en las construcciones arquitectónicas en tanto que proporciones ideales y presencia de columnas antropomórficas con atributos de género y de metonimias arquitectónicas explícitas.

A partir de la Revolución Industrial se inicia en Europa un periodo dominado por la racionalidad y la creencia en el progreso, lo que desencadena un movimiento migratorio masivo del campo a la ciudad. El hacinamiento de la población obrera en barrios periféricos insalubres, la concentración de humedad, la alimentación deficiente y las jornadas de trabajo extenuantes son el caldo de cultivo para la propagación de las enfermedades epidémicas. Desde principios del siglo xIx se comienzan a construir balnearios y espacios sanatoriales específicamente dedicados al aislamiento y tratamiento de enfermos de tuberculosis (Ruiloba Quecedo, 2014). Se ubican en puntos estratégicos alejados de las concurridas ciudades, en lugares montañosos y secos, buscando las mejores condiciones de soleamiento y aire puro. La arquitectura comunica directamente el interior (habitaciones) con el exterior (entorno natural) a través de galerías de reposo.

El modelo institucional se diseña antes del descubrimiento del agente etiológico (1882), por lo que se practica un tratamiento dietético e higiénico basado en largos ingresos, incluso de años (Duarte y López, 2009). La apariencia externa como casa de descanso no resta sensación de enclaustramiento al enfermo. Así es como lo transmite Elaine Whittaker en su instalación Contained (2018) al simbolizar a su madre como un pájaro encerrado en un sanatorio de la zona rural de Quebec en 1944. A los veinte años, y como consecuencia de los 


\section{artnodes}

https://artnodes.uoc.edu

cuidados hacia su hermano y su cuñada, que padecían tuberculosis, se contagia e ingresa en la institución para recibir los tratamientos vigentes en ese momento en rigurosa planificación diaria, como corresponde a la visión de Foucault (2009) sobre los hospitales como máquinas de curar. La habitación de mobiliario blanco vislumbra la ausencia de un cuerpo de mujer enfermo: el colchón se ha sustituido por un tapete de croché y se repiten objetos sobre las mesillas y la pared que redundan en elementos procedentes de pájaros «contenidos» en instrumental transparente de laboratorio, como tubos de ensayo, placas de Petri y cubeta de electroforesis (figura 1). La situación de claustrofobia, la continua vigilancia, así como el largo y agresivo tratamiento dejaron en la madre de Whittaker una huella imborrable para el resto de su vida que se tradujo en una obsesión por la higiene transmitida a sus hijos. La práctica artística de Elaine Whittaker tiene su origen en la investigación microbiológica. Tal y como apunta en su página web, «me di cuenta de que la mayoría de los microbios no son infecciosos, son más inofensivos que dañinos y nuestra relación simbiótica con ellos es parte de nuestro propio bienestar». Este aspecto bondadoso que otorga
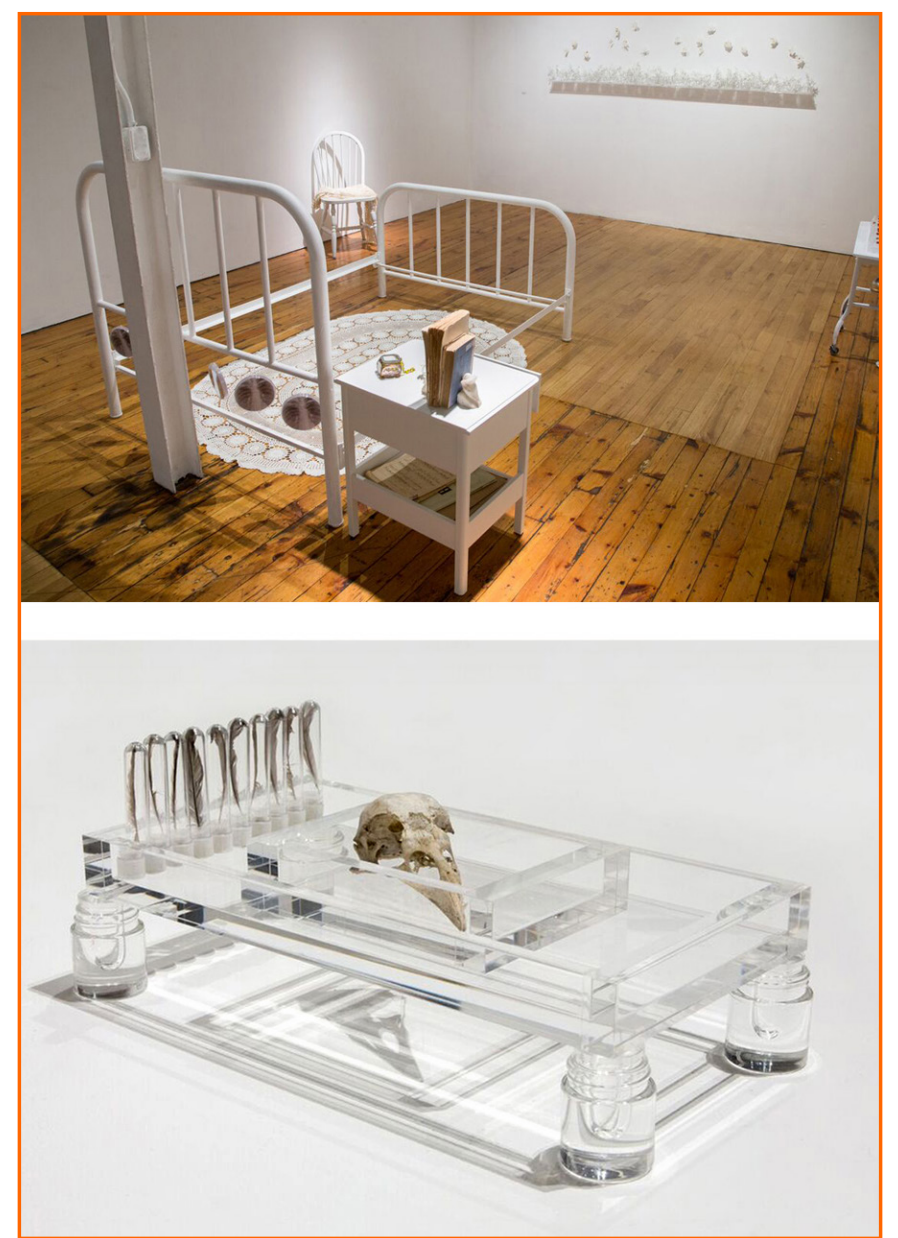

Figura 1. Elaine Whittaker. Arriba, vista general de la instalación Contained (2018). Abajo, una de las piezas, At Rest: Flight (2018). Fuente: https://www.elainewhittaker.ca/.
Arte contemporáneo y arquitecturas del cuerpo contagiado (huésped-hospedador) bajo la narrativa del sanatorio antituberculoso

al mundo microbiano no ha conseguido mitigar la incertidumbre y el miedo a la hospitalización, como deja patente en Fraught Air (2018), más de cincuenta máscaras de oxígeno utilizadas actualmente en hospitales colgadas en una pared, recordándonos que la tuberculosis aún no ha sido erradicada.

El tratamiento metafórico del ingreso de la madre de Elaine Whittaker en una habitación de un hospital durante dos años contrasta con la visión objetiva y fría de la artista Carol Jerrems, ingresada durante tres meses con el síndrome de Budd-Chiari en 1979 justo antes de su muerte a los treinta años, tras recibir el alta médica. En su serie fotográfica The Royal Hobart Hospital (1979) somete las dependencias de la institución a la mirada panóptica del objetivo de su cámara. Una especie de vigilancia vigilada o de observador observado 0, en palabras de Colomina (2006b), de doble exposición. La transparencia de la ventana del despacho con los registros médicos, colocados en estanterías, permite captar la reunión del médico con las enfermeras, quienes atienden las pautas para llevar con los enfermos (figura 2, arriba). En otras dos fotografías el médico observa una

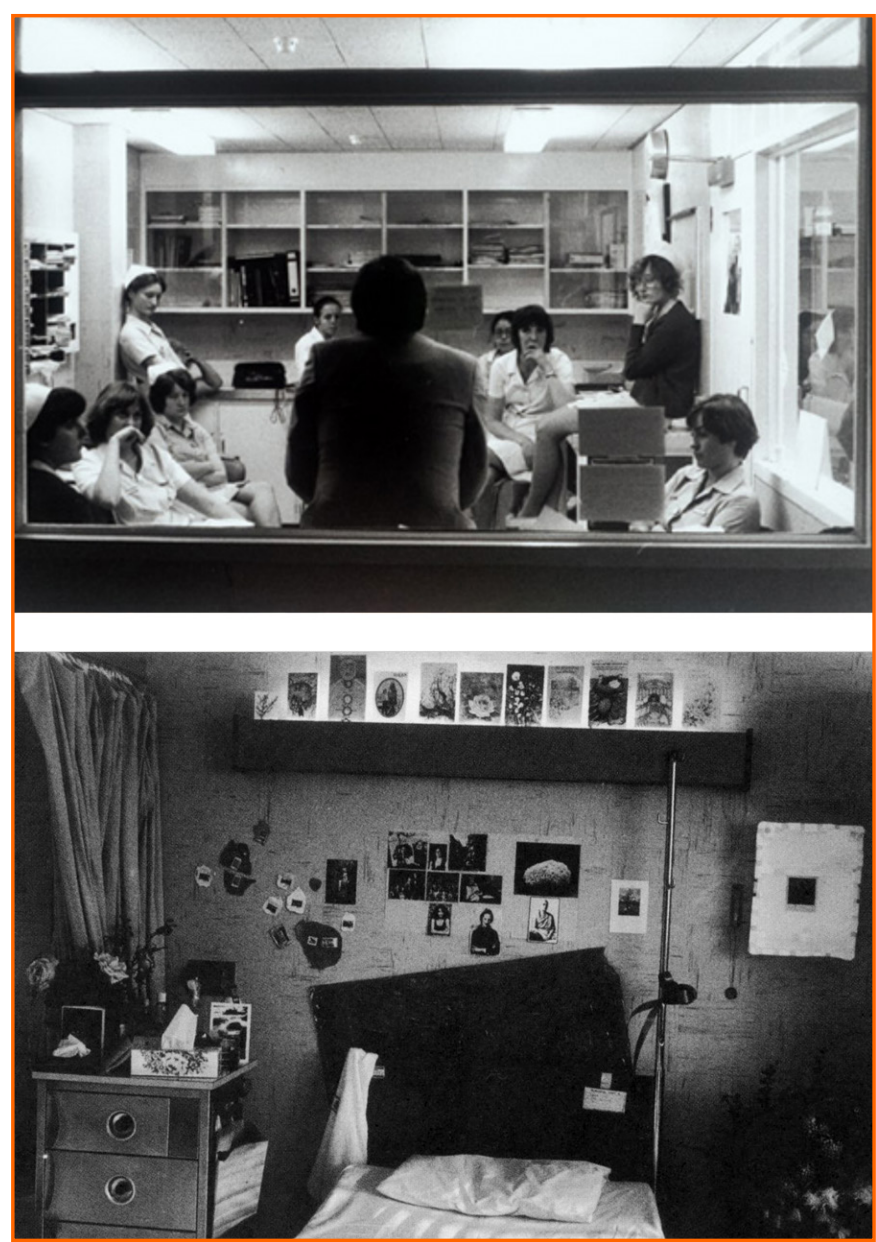

Figura 2. Carol Jerrems. Fotografías pertenecientes a The Royal Hobart Hospital Series, (1979). Fuente: https://www.portrait.gov.au/images/13891. 


\section{artnodes}

https://artnodes.uoc.edu

radiografía al trasluz y una enfermera bloquea la mirada de la cámara con una cortina divisoria de espacios antes de comenzar con la rutina del tratamiento con una relativa intimidad. En habitación ocupada por Jerrems, los objetos personales, fotografías y flores reflejan la personalización del espacio (figura 2, abajo). Sin embargo, se trata de objetos fácilmente transportables que se lleva el enfermo una vez recibe el alta, en este caso por el carácter incurable (desahucio), o que son eliminados si fallece y no son reclamados por sus familiares.

Uno de los principales hitos de la medicina que influirá en los sanatorios y posteriormente en las unidades de infectocontagiosos de los hospitales es la teoría de las enfermedades infecciosas trasmisibles. En los sanatorios se incluyen hornos crematorios para destruir ropas y enseres de fallecidos, se agudiza el miedo al contagio potenciando las medidas higiénico-sanitarias y se criminaliza y rechaza al infectado. Si bien para los más pobres ingresar en un sanatorio antituberculoso suponía la liberación de cargas familiares y de la vida en hacinamiento (Duarte, 2015), para la mayoría el aislamiento tenía una connotación de ocultamiento del resto de la sociedad (Paniagua Caparrós, 2014). En el imaginario social obrero la tuberculosis queda representada por el tísico como foco de infección que debe ser apartado y controlado para asegurar la salud física y moral de las clases burguesas. Este imaginario tísico-pobre lo encontramos en los años ochenta con la propagación del SIDA, enfermedad vírica de transmisión sexual que dio lugar al binomio sidoso-homosexual. Las características de esta enfermedad desde un punto de vista antropológico las refleja el artista Pepe Miralles en la serie Etnografía de una enfermedad social, iniciada en 1993. El título hace referencia a la ocultación (SIDA) para resaltar el rechazo (enfermedad social). Ajuares (1995-1997) es la última pieza resultante de la serie, un registro material de acompañamiento hacia la muerte de su amigo Juan Guillermo en sus últimos años de vida, en los que el hospital se traslada a su domicilio particular. Los ritos asociados al tratamiento médico son llevados a cabo por los amigos íntimos del enfermo, entre ellos Pepe Miralles, que guarda y plastifica individualmente los restos de enseres y material sanitario (jeringuillas, bolsas de suero, gasas y guantes desechados, cajas de AZT, etc.) que iba utilizando para ayudar al enfermo a transitar en su dolencia. La recopilación finaliza en mayo de 1995, tras la muerte. El cuidado de su amigo en aquel hospital domiciliario se convierte en una experiencia real que, tal y como expresa el propio artista, «A la sazón no sabía que, de alguna manera, me estaba dando su cuerpo a trozos» (Miralles, 2017), fragmentos que recompone a modo de archivo en vitrinas horizontales de madera que remiten a ataúdes.

Si bien la arquitectura moderna tal y como se inauguró hace un siglo conserva su vigencia en tanto que condiciones higiénicas y de ventilación, las actuales epidemias y pandemias plantean nuevas reflexiones sobre si los hospitales, ciudades sanitarias, hospitales en red e incluso pabellones efímeros improvisados y los avances biotecnológicos asociados a la sanidad, determinarán y han determinado una transformación en las viviendas unifamiliares del siglo xxı. Al contrario
Arte contemporáneo y arquitecturas del cuerpo contagiado (huésped-hospedador) bajo la narrativa del sanatorio antituberculoso

que los sanatorios antituberculosos, los hospitales se diseñan para que la estancia dure el mínimo tiempo posible. Aumenta el número de laboratorios de alta tecnología y quirófanos que utilizan técnicas láser menos agresivas (Corea, 2015). Disminuye el número de estancias con camas, que son suplantadas por un régimen ambulatorio en el que el hospital se traslada al domicilio privado (confinamiento absoluto) 0 al propio espacio urbano, con barreras de metacrilato y señalética para favorecer la circulación con el distanciamiento social suficiente para frenar la difusión de los agentes. El hospital como institución arquitectónica ya no es un recinto delimitado por cuatro paredes. El cuerpo enfermo accede al médico a través de plataformas y sedes electrónicas de la institución sanitaria, se autoexplora y envía sus síntomas para ser procesados antes de recibir su tratamiento. Su caso queda registrado numéricamente para pasar a formar parte de una base de datos, representada por Damien Hirst en su instalación A Way of Seeing (2000) por un doble cubículo de cristal en cuyo interior un técnicorobot analiza unas muestras a través del microscopio (figura 3). Hirst enfatiza el privilegio de la visión en el uso diagnóstico y resalta la ausencia de la asistencia médica y su sustitución por la intervención tecnológica, que tiene que ver con el modelo de muerte medicalizada y silenciosa del siglo XXI, cuyas bases teóricas anticipa Ariès (1977).

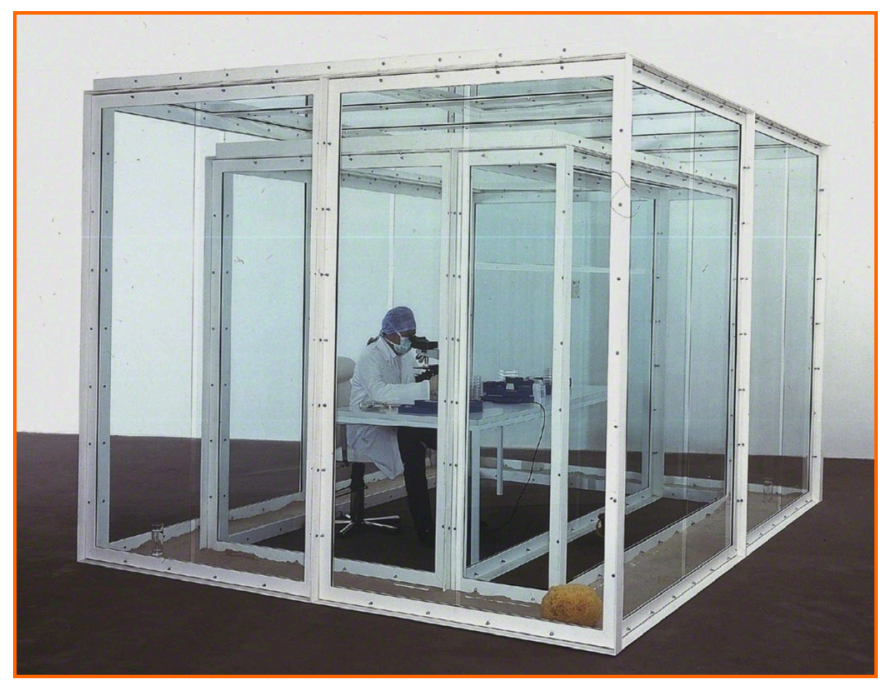

Figura 3. Damien Hirst. A Way of Seeing (2000). Fuente: http://www.damienhirst.com/

\section{El cuerpo enfermo como hospedador. "Alojar a"}

El descubrimiento de los rayos $X$ a finales del siglo xix y su aplicación en el diagnóstico de enfermedades impactó en el trabajo de arquitectos de vanguardia de las primeras décadas del siglo xx. Para Colomina (2019) la arquitectura moderna es como el cuerpo atravesado por rayos X en el que desaparece la piel (Skinless Architecture). El vidrio de los grandes ventanales (piel) que deja pasar la radiación (aire), 


\section{artnodes}

https://artnodes.uoc.edu

visibiliza (ventila) la estructura (órganos y tejidos internos) para conseguir un interior en el que desarrollar actividades de manera saludable. Ludwig Mies van der Rohe compara su Rascacielos de Cristal de 1922 con el cuerpo humano observado a través de los rayos $X$. El vidrio transparente que recubre la arquitectura es la piel que deja ver la estructura o esqueleto. Glass Skyscraper de Le Corbusier (1925) y Bauhaus de Walter Gropius (1926) son otros ejemplos citados por Colomina para compararlos con radiografías de tórax.

Desde un punto de vista antropológico, la visualización del interior del cuerpo con rayos $\mathrm{X}$ tiene unas connotaciones que son analizadas por Guerrero Ortega (2010). La ilusión de transparencia de las profundidades del cuerpo propio o ajeno se corresponde con la creciente demanda de realidad inmediata de la cultura contemporánea, en la que las fronteras entre lo público y lo privado se han disuelto completamente. Sin embargo, surgen dos cuestiones que problematizan la visualización. Por una parte, el individuo-cuerpo perceptivo en contacto con el exterior se enfrenta a un espacio homogéneo y opaco formado por vísceras, entrañas y huesos, con el que no se identifica y le es extraño. Por otra, toma conciencia de la necesidad del interior para su existencia. La resolución de esta dualidad ontológica (lo extraño frente a la pertenencia) a través de la visualización y el conocimiento amortigua la angustia básica de no poder controlar lo que nos habita.

El conocimiento necesario para comprender el interior del cuerpo es literalmente visual, a modo de anatomía morfológica, en la obra de Rachel Whiteread. Sus vaciados de espacios arquitectónicos, moldes exactos del interior, cuentan historias, hablan y, por tanto, es necesario someterlos a un interrogatorio. Como apunta Colomina (2006b, p. 141) el edificio de Whiteread es el «cuerpo patológico de la medicina de finales del siglo xx, el sujeto a procedimientos cada vez más invasivos y violentos, cuyo interior es necesario ver con mayor detalle a fin de, controlado, diagnosticado, intervenir en él». La extracción de datos a partir del individuo como colectivo y su procesado constituyen una valiosa información para establecer las cifras epidemiológicas de la enfermedad. Son estadísticas en las que basar una buena planificación política sanitaria 0 a partir de las que hablar de la inversión en sanidad pública de un país. La Línea de Sangre de Adolfo Bimer (2018) es un ejemplo gráfico de la alienación

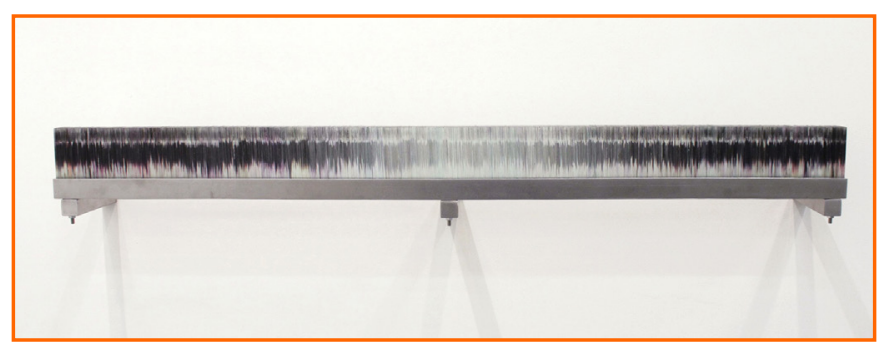

Figura 4. Adolfo Bimer. 292: Línea de sangre (09/10/17 - 13/10/17), (2018). Fuente: http:// adolfobimer.com/
Arte contemporáneo y arquitecturas del cuerpo contagiado (huésped-hospedador) bajo la narrativa del sanatorio antituberculoso

y anonimato del tratamiento de datos. Compuesta de portaobjetos con extensiones de sangre extraída de diferentes pacientes, sus perfiles perfectamente alineados dibujan en conjunto una línea similar a los histogramas de un estudio estadístico (figura 4).

La transparencia de la piel, así como la posibilidad de atravesarla para la extracción de datos es importante desde el punto de vista del diagnóstico, pero al mismo tiempo permite al cuerpo ser un perfecto anfitrión ante la llegada de microorganismos extraños, los cuales encuentran un lugar lo más parecido a una casa en tanto que protección y disponibilidad de alimentos. Las interpretaciones del artista contemporáneo relacionadas con conceptos arquitectónicos a los que nos estamos refiriendo en nuestro estudio tienen que ver con la posibilidad de entrada e invasión del interior del organismo, las armas de las que dispone el microorganismo para vencer los mecanismos de defensa del hospedador y con la aplicación de los conocimientos científicos en la prevención, fundamentalmente en la fabricación de vacunas específicas. El cuerpo se encuentra amenazado e indefenso ante lo que es metafórica y realmente hablando la nueva forma de guerra: la pandemia.

La idea de diferentes imaginarios sociales alojados en mejores o peores arquitecturas construidas a partir de la idea del sanatorio antituberculoso queda difuminada y convertida en un cuerpo único que aloja al invasor con un código genético que no diferencia jerarquías ni fronteras. Wangechi Mutu reproduce esta idea en su serie Virus (2016), esculturas magnificadas de virus del Ébola, el VIH, y el virus Zika, productores de enfermedades cuyo origen está en África, fabricados con pulpa de papel y recubiertos con arcilla. La artista reflexiona sobre dos tipos de invasión: la producida por cada uno de los virus tras la entrada y multiplicación en el interior del hospedador y la invasión colonial británica de Kenia, con la consiguiente difusión de su cultura acompañada de la introducción del virus de la viruela.

En la actualidad, los avances médicos contra estas enfermedades se basan en el conocimiento de las armas de defensa del propio cuerpo hospedador y de las estructuras internas de los agentes transmisibles. Así, el ilustrador científico que en el pasado reproduce la anatomía y los cortes histológicos del interior del cuerpo y las primeras bacterias observadas al microscopio óptico tras su tinción, se interesa actualmente por un mundo que amplifica hasta un millón de veces y presenta con toda la información posible. La serie Glass Microbiology, iniciada por Luke Jerran en 2004, reúne reproducciones en vidrio transparente de virus como el de la gripe porcina y del Ébola (figura 5, arriba). Sus cristalerías desafían los convencionalismos de colorear artificialmente las imágenes microbiológicas y se presentan como joyas sobre superficies iluminadas, generando así una tensión provocada por la contemplación de la belleza de las piezas y el conocimiento de la peligrosidad de aquello que representan. Y es que, como afirma en su web la artista Laura Splan, «el bioterrorismo, las pandemias y los productos antimicrobianos por igual han 


\section{artnodes}

https://artnodes.uoc.edu

aumentado nuestra conciencia del mundo microbiano». Su proyecto Doilies (2004) evidencia la domesticación de imágenes microbianas y biomédicas en el paisaje cotidiano mediante el tejido de diferentes tipos de virus a modo de tapetes que tradicionalmente recubren el mobiliario del hogar (figura 5, abajo). Tanto Jerran como Splan han completado sus series con el actual agente causal de la pandemia COVID-19, desempeñado un papel destacado durante las crisis: las imágenes de Jerran han sido utilizadas internacionalmente para la difusión científica, mientras que los tapetes de Splan han adquirido una nueva resonancia bajo el lema «Quédate en casa».
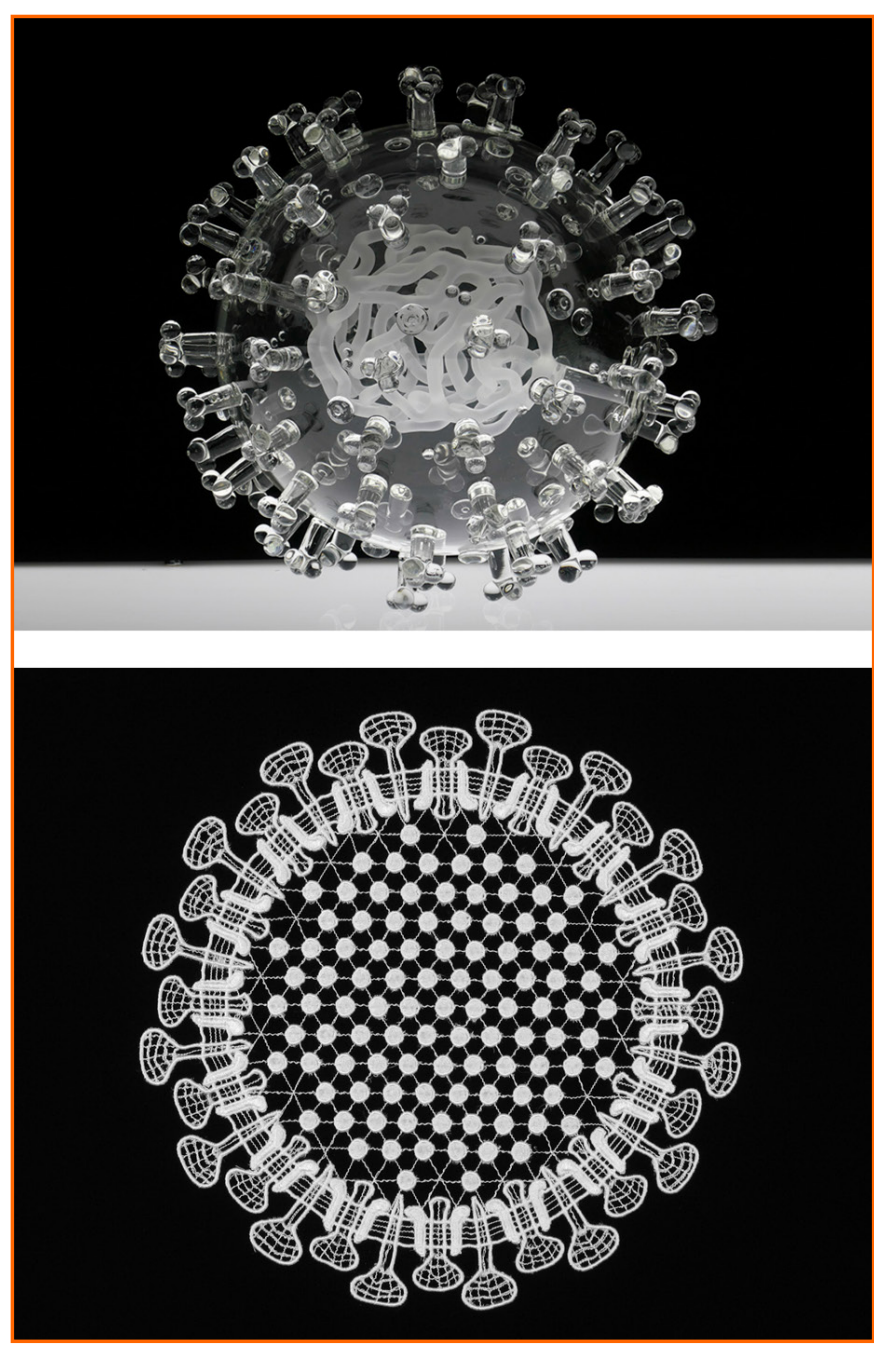

Figura 5. Arriba, Luke Jerran. Coronavirus Covid-19 (2020), de la serie Glass Microbiology Fuente: https://www.lukejerram.com/. Abajo, Laura Splan. SARS (2004), de la serie Doilies. Fuente: http://www.laurasplan.com/.

La estructura molecular es el grado máximo de transparencia de los contenidos albergados en el interior de los microorganismos. Su conocimiento parte de la descripción de la composición del ADN obtenida por difracción de rayos $\mathrm{X}$ y explica el modo de codificar la
Arte contemporáneo y arquitecturas del cuerpo contagiado (huésped-hospedador) bajo la narrativa del sanatorio antituberculoso

información contenida en los genes. La ciencia médica se centra actualmente en la aplicación de la genética en la fabricación de vacunas, seleccionando aquellas partes del microorganismo que son fundamentales en la entrada a la célula del hospedador para causar la lesión y tratando de neutralizarlas. La artista Katharine Dowson representa el trímero que podría ser la vacuna contra el virus del VIH. Su obra $A$ window to a future of an HIV vaccine (2015) está formada por ocho bloques transparentes (figura 6), uno por cada grupo de científicos participantes en este proyecto de lucha contra el SIDA que, al unirse, contienen la molécula responsable de la fijación del virus VIH a los linfocitos antes de infectarlos.

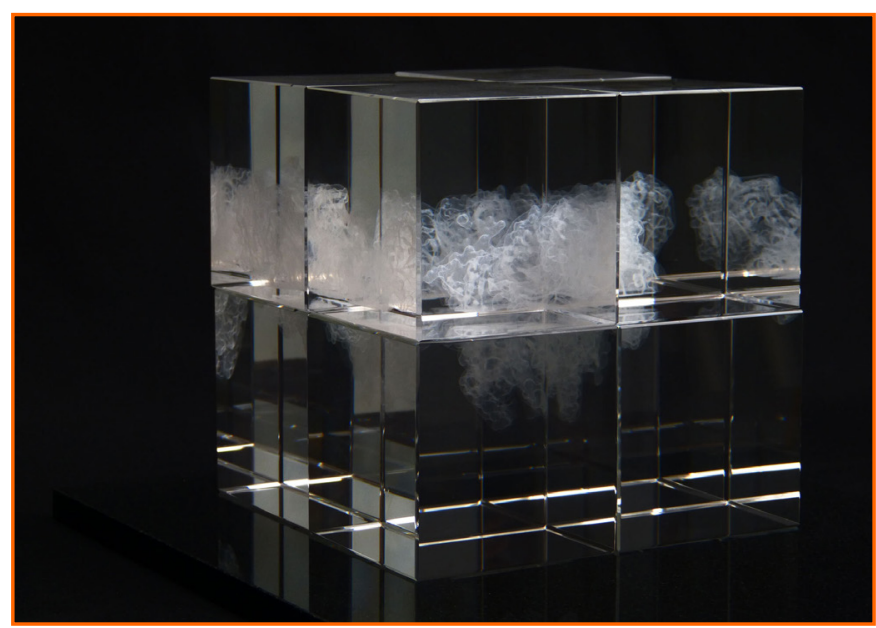

Figura 6. Katharine Dowson. A window to a future of an HIV vaccine (2015). Fuente: https:// katharinedowson.com/.

La alta tecnología en la medicación del cuerpo enfermo en general y del cuerpo infectado por un agente microscópico en particular, así como una medicina preventiva basada en la caracterización de moléculas en la elaboración de vacunas, ha venido a ampliar el espacio arquitectónico antes limitado a los hospitales. Ravanal y Aurenque Stephan (2018) sugieren que el exceso de información en la percepción subjetiva de una persona sobre su propia salud es fuente de inquietud y ansiedad que aboca en el hiperconsumo y pone de nuevo sobre la mesa las desigualdades en el acceso a la medicina. Bajo esta consideración, el poder sobre el cuerpo ejercido en las cuatro paredes de la habitación-estancia de la máquina de curar foucaultiana, se centra ahora en el control de un cuerpo que circula por los espacios públicos y privados bajo el yugo de los avances tecnológicos en medicación preventiva o curativa.

\section{Conclusiones}

A lo largo del presente estudio ponemos de manifiesto que los avances médicos sobre las tres grandes epidemias de los siglos $x x$ 


\section{artnodes}

https://artnodes.uoc.edu

y xXI (tuberculosis, SIDA y SARS) han marcado importantes cambios en aspectos de la sociedad, entre ellos las maneras de habitar el espacio físico y virtual. Los primeros sanatorios antituberculosos en los que se controla al individuo durante largas temporadas en lugares apartados acaban convirtiéndose en hospitales y ciudades sanitarias urbanas que acogen a pacientes durante el mínimo tiempo posible. Paralelamente, y como consecuencia de la posibilidad de percibir el interior anatómico, el cuerpo-individuo enfermo aislado en el sanatorio antituberculoso en el siglo xix es un cuerpo-colectivo contenedor de datos que son procesados para su uso como control de espacios más amplios, países y continentes.

Si bien es evidente la recurrencia temática de la enfermedad en el arte contemporáneo debido, en parte, a que se trata de una experiencia universal, su complejidad y carácter multidisciplinar conduce al artista a resaltar algunas de las facetas del imaginario poliédrico de la enfermedad. El planteamiento de nuestra investigación está dirigido hacia el análisis de una selección de trabajos desde un enfoque arquitectónico, en el que proponemos un cuerpo que es sujeto-huésped de espacios para la contención de la enfermedad y al mismo tiempo sujeto-hospedador atravesado por la mirada diagnóstica médica y por el agente invasor. El recorrido que realizamos bajo el enunciado de cuerpo alojado demuestra el cambio de paradigma del primigenio sanatorio antituberculoso, reflejado en las experiencias indirectas y directas de artistas ingresados en instituciones sometidas al control médico, hasta los actuales hospitales Big Data, pasando por la presencia del cuerpo con SIDA en su domicilio mientras aguarda la muerte. Bajo el concepto de cuerpo que aloja, resaltamos la puesta en evidencia de la visibilización del interior para el estudio de los órganos internos del paciente como contenedor de información y la permeabilidad al contagio por agentes infecciosos. Estas obras se caracterizan por el rigor científico y la representación fiel de estructuras y técnicas biomédicas, puesto que emanan de la investigación y el conocimiento para hacer frente a la amenaza que supone el exceso de información al alcance de todos.

\section{Referencias bibliográficas}

Ariès, Philippe. 1977. L'Homme devant la mort. París: Seuil.

Colomina, Beatriz. 2006a. La Domesticidad en Guerra. Barcelona: Actar.

Colomina, Beatriz. 2006b. Doble exposición. Arquitectura a través del arte. Madrid: Akal.

Colomina, Beatriz. 2019. X-Ray architecture. Zürich: Lars Müller.
Arte contemporáneo y arquitecturas del cuerpo contagiado (huésped-hospedador) bajo la narrativa del sanatorio antituberculoso

Corea, Mario. 2015. «El hospital del siglo xxl: Continuidad y especificidad». Anuario 2015. AADAIH. Asociación Argentina de Arquitectura e Ingeniería Hospitalaria, 80-93.

Duarte, Ignacio y López, Marcelo. 2009. «Importancia del reposo en los sanatorios para tuberculosos». Revista Chilena de Infectología, 26(3): 273-278. D0l: http://dx.doi.org/10.4067/S071610182009000400013.

Duarte, Ignacio. 2015. «Sanatorios para tuberculosos: auge y decadencia». Revista Médica Clínica Las Condes. 26(3): 409-418. D0l: https://doi.org/10.11565/arsmed.v34i2.216.

Dyer, Carol. 2010. Tuberculosis. Santa Bárbara, California: Greenwood.

Foucault, Michel. 2009. Vigilar y castigar: nacimiento de la prisión, Madrid: Siglo XXI.

Guerrero Ortega, Francisco Javier. 2010. El Cuerpo incierto. Corporeidad, tecnologías médicas y cultura contemporánea. Madrid: Consejo Superior de Investigaciones Científicas.

Iglesias Picazo, Pedro. 2011. La habitación del enfermo: ciencia y arquitectura en los hospitales del Movimiento Moderno. Barcelona: Fundación Caja de Arquitectos.

López del Rincón, Daniel. 2015. Bioarte. Arte y vida en la era de la biotecnología. Madrid: Akal.

Miralles, Pepe. 2017. «Etnografía de una enfermedad social». Kamchatka. Revista de análisis cultural, 10: 279-288. D0I: https://doi. org/10.7203/KAM.10.11033

Navarro, Fernando. 1997. Traducción y lenguaje en medicina. Barcelona: Ediciones Doyma.

Paniagua Caparrós, José León. 2014. «Transatlánticos varados». Arquitectura Sanitaria: Sanatorios Antituberculosos. Madrid: Escuela Nacional de Sanidad. Instituto de Salud Carlos III. Ministerio de Economía y Competitividad.

Ramírez, Juan Antonio. 2003. Edificios-cuerpo. Cuerpo humano y arquitectura: analogías, metáforas, derivaciones. Madrid: Siruela. D0I: https://doi.org/10.24310/BoLArte.2002.v0i23.4748

Ravanal, Martín de la, y Aurenque Stephan, Diana. 2018. «Medicalización, prevención y cuerpos sanos: la actualidad de los aportes de Illich y Foucault». Tópicos, 55: 407-437.

Río Almagro, Alfonso del, y Rico Cuesta, Marta. 2019. «La enfermedad como otredad: Las metáforas dominantes a partir de las prácticas artísticas visuales». AIBR. Revista de Antropología Iberoamericana, 14(2): 253-276.

Ruiloba Quecedo, Cecilia. 2014. Arquitectura Sanitaria: Sanatorios Antituberculosos. Madrid: Escuela Nacional de Sanidad. Instituto de Salud Carlos III. Ministerio de Economía y Competitividad4.

Sontag, Susan. 1979. IIIness as metaphor. New York: Vintage Books. 


\section{artnodes}

https://artnodes.uoc.edu

\section{CV}

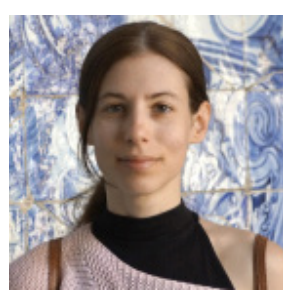

\section{Gloria Lapeña Gallego}

Departamento de Dibujo. Universidad de Granada

lapena@ugr.es

Doctora por la Universidad de Murcia, Menciones Cum Laudey Doctor Internacional. Profesora Ayudante Doctora en la Facultad de Bellas Artes de la Universidad de Granada desde 2018. Secretaria técnica de la revista científica Arte y Políticas de Identidad de la Universidad de Murcia desde 2016. Actualmente colabora en el proyecto Genealogy of ideas Genius loci and accumulation of collective memories in Europe. A Socio-religious history (Japan Society for the Promotion of Science and Tokyo University of Foreign Studies) y es investigadora principal del proyecto Orar, coser y lavar. Arqueologías y memoria en el espacio público femenino como huella del presente (Vicerrectorado de Igualdad, Inclusión y Sostenibilidad de la Universidad de Granada). Su faceta investigadora, ligada a su labor artística, se circunscribe en el espacio urbano y las arquitecturas como receptáculo de memorias paralelas e identidades soslayadas por la historiografía oficial. bajo la narrativa del sanatorio antituberculoso
bel cuerpo contagiado (huésped-hospedador) 